\title{
Application of integrated marketing communication in pharmaceutical industry
}

\author{
Ashok Panigrahi ${ }^{1, *}$, Komal Aware $^{2}$, Akshay Patil ${ }^{3}$ \\ ${ }^{1}$ Associate Professor, ${ }^{2,3}$ Student, NMIMS University, Shirpur, Maharashtra, India
}

Corresponding Author:

Email: panigrahi.ak@gmail.com

\begin{abstract}
Integrated Marketing Communication is a business process or a strategy used to plan, develop, execute for brand communication program or to describe the product to your customers. The advancement of powerful communication mix in pharmaceutical advertising is complex task which identifies the target audience, deciding the correspondence targets, designing a message, choosing method of delivery and collecting feedback. Pharmaceutical promotion is divided in two phases' in-clinic and out-ofclinic which includes information leaflets, samples, gifts and clinical-trails, seminars, camps, advertisement, etc. The paper describes about Marketing mix which includes product mix, price mix and distribution channels. It also differentiate the promotional tools like internet based, Electronic detailing, Personal selling, E-Sampling used synergistically for prescription and OTC drugs while promoting the pharmaceutical products by using Integrated Marketing Strategy. Pharmaceutical industry faces many challenges like regulatory barriers and doctor's non-readiness for prescribing the drug products this can be overcome by convincing doctors by providing them adequate information about the quality of product and advantages over competitor's edge whereas in case of regulatory they must follow the norms led down by the authorities.
\end{abstract}

Keywords: IMC, Pharmaceutical, OTC, Marketing Mix, FDA.

\section{Introduction}

For every business to grow and prosper requires a proper communication and creating relationship with customer by identifying and fulfilling their needs which is easy for consumer products. Pharmaceuticals market is highly regulated, and it can be stated that prescription (legal or ethical) drugs have a status of substances in controlled circulation also has over the counter products with less or no legal restrictions. Promotional activities are also under strict legislation, further burdened with ethical consideration and public scrutiny. In case of pharmaceutical products the aim of promoting is to inform consumer and health care professionals about new treatments by either Direct-to-Consumer (DTC) by advertisement in order to make customer aware of new treatments available and to health care professionals by sales representative to give them up to date and accurate information about new chemical entities.
Pharmaceutical market is generally integrated at three levels includes marketing mix components (product, price and method of distribution, promotional tools and the strategy of company. The basic marketing objective in case of pharmaceuticals is that both product chain and prescription chain meet at the end, this can be achieved by informing doctor by the sales team either through in-clinic promotion or out-of-clinic promotion/marketing .In-Clinic Promotional/Communication Mix includes detailing aid; leave behind material, samples, gift/giveaways, and direct mailers. Out-of-Clinic Promotional/Communication Mix includes clinical trials/studies, seminars/symposia/round table discussion sponsorships, film shows, advertisements, public relations, free medical camps, corporate marketing, hospital/ward improvement programs, E-marketing which result in Direct-to-consumer promotion.

\section{Marketing-Mix Components in Pharmaceuticals}

\begin{tabular}{|l|l|}
\hline Integrated Marketing Communication & Traditional Marketing Communication \\
\hline $\begin{array}{l}\text { 1. Cooperative energy work: Integrated } \\
\text { into one. }\end{array}$ & 1.Separated capacity confinement \\
$\begin{array}{l}\text { 2. Client Oriented: begin with the client } \\
\text { needs. }\end{array}$ & $\begin{array}{l}\text { 2.Association Oriented: begin with the } \\
\text { objectives and item }\end{array}$ \\
$\begin{array}{l}\text { 3.Lucid correspondence programs } \\
\text { 4.Mark/Relationship building objective } \\
\text { 5.Focused to partner section }\end{array}$ & $\begin{array}{l}\text { 3.Breaking correspondence programs } \\
\text { 4.Fleeting deals objective }\end{array}$ \\
5.Boundless gathering of people
\end{tabular}


IMC Model: In general the IMC Model works as follow:

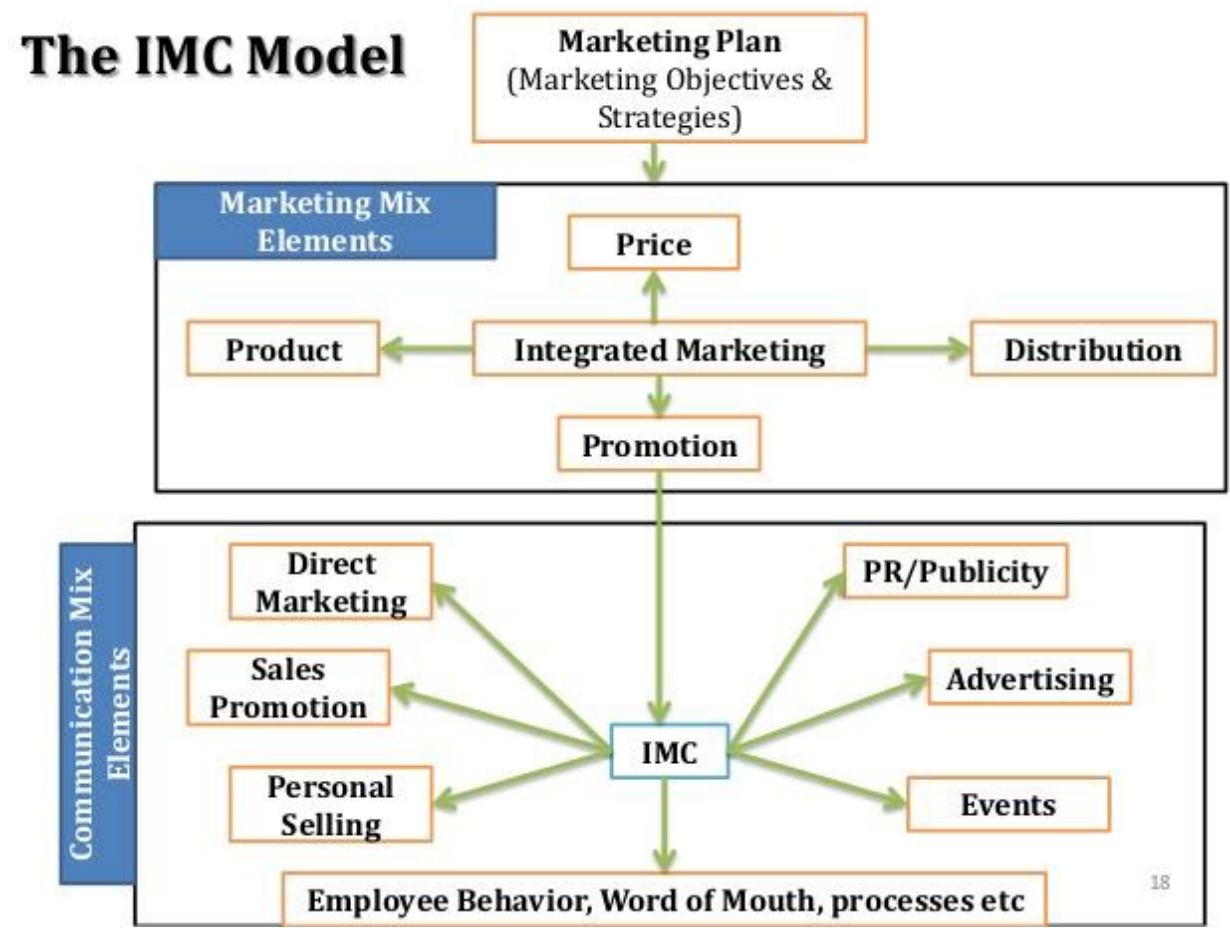

Source: https://www.slideshare.net/nijazn/introduction-to-advertising-integrated-marketing-communication

How the model works in pharmaceutical industry is explained below:

1. Product mix indicates the decisions of the firm regarding the product design, product range, product packing, product quality, product branding, product labelling and after sale service. In case of pharmaceutical products out of all these parameters the most important that a product should fulfil is that of quality for which the standards are led down by regulatory agencies, the design of pharma product depends upon the targeted disease and route by which the drug need to be introduced whereas the other parameters like packing, labelling are depended upon the characteristic or nature of the drug that is to be packed and the labelling specifications are decided by the regulatory authorities.

2. Price mix reflects the managerial decisions of the business pertaining to pricing policies and strategies, terms of credit, terms of delivery, margin of profit, discount and allowances. The products we are discussing, their pricing depends upon the investment made for research and development by the organization and also the pricing of product is being controlled by some government committees' like in India Drug Price Control Order(DPCO).This is done in order to make the important medicines available to every income group at affordable prices. Regulatory factors should be considered while pricing. E.g. In the Pharmaceutical Market, there are Key Accounts which are belonging to Governmental sector or ministry of health sector (M.O.H.) who are obligated to decrease their pricing strategy by

$50-80 \%$ to make their product available for the end-consumers in those sectors. So really the key account management and relationship marketing are playing an essential role in helping your organization to get best pricing strategies in those sectors.

3. Distribution Channels: Distribution is the only element in the marketing mix that makes the product of the manufacturer available to the customers. No matter how excellent the other elements of the marketing mix are, a firm cannot succeed in today's competitive world without good distribution channel strategy; i.e. the product of the manufacturer should be at the right place at the right time.

\section{Promotional Tools}

1. Advertising: Any paid type of non-personal communication and promotion of ideas, products, or services by a distinguished support (sponsor).

2. Personal selling: Personal presentation by the firms sales force to make sales and build customer relationship.

3. Sales advancement: Short-term motivations to support the buy or sale of a item or services by offering discounts or offers. 
4. Public relations: Building great relations with the organization's publics by getting ideal attention, developing a decent "corporate picture," and taking care of or handling negative gossipy, stories, and unfavourable occasions or events.

5. Direct advertising: Direct interaction which is precisely focused on grabbing purchaser's attention or to acquire a quick reaction by utilization of mail, phone, fax, email, and other non-individual aid to discuss straightforwardly with the seller. Table 1 Promotional tools used in marketing communications on the RX and OTC markets.

\begin{tabular}{|c|c|}
\hline RX Drugs & OTC Drugs \\
\hline $\begin{array}{l}\text { 1.Advertising: authority squeeze productions, } \\
\text { tended to specialists, drug specialists, data } \\
\text { hand-outs }\end{array}$ & $\begin{array}{l}\text { 1.Advertising:TV,squeeze, radio, posters, } \\
\text { BTL media (promotional materials in drug } \\
\text { stores, surgeries, timekeepers ,timetables, } \\
\text { flyers, flyers, data flags and so on.), } \\
\text { surrounding media itemizing, CLM (Closed } \\
\text { Loop Marketing) }\end{array}$ \\
\hline $\begin{array}{l}\text { 2.Personal offering - restorative delegate } \\
\text {,bolster through new advancements e- } \\
\text { specifying, CLM (Closed Loop Marketing) }\end{array}$ & $\begin{array}{l}\text { 2.Personal offering drug specialist's } \\
\text { recommendation }\end{array}$ \\
\hline $\begin{array}{l}\text { 3. Sales advancement: giving supplies using a } \\
\text { credit card to wholesalers and drug stores, } \\
\text { free examples of medications for specialists, } \\
\text { rebates for discount buys, bundle bargains for } \\
\text { drug stores, reliability programs. }\end{array}$ & $\begin{array}{l}\text { 3.Sales advancement: greater bundle at a } \\
\text { similar cost, rebates, extra item with the buy } \\
\text { of the essential medication, vouchers, } \\
\text { rivalries, devotion rewards }\end{array}$ \\
\hline $\begin{array}{l}\text { 4. Public Relations - promoting occasions, } \\
\text { preparing for specialists and drug specialists, } \\
\text { campaigning, sponsorship, visual } \\
\text { recognizable proof framework, media } \\
\text { relations, counselling programs for drug } \\
\text { stores. }\end{array}$ & 4. Drug store marketing \\
\hline 5.e-pharmamarketing & $\begin{array}{l}\text { 5.Public relations: sponsorship, exposure, } \\
\text { promoting occasions for specialists, drug } \\
\text { specialists, patients } \\
\text { 6.Product situation (setting an OTC } \\
\text { medication in a motion picture or a TV } \\
\text { arrangement) } \\
\text { 7. e-pharm marketing }\end{array}$ \\
\hline
\end{tabular}

In total we can say that pharmaceutical sale, marketing and distribution is evolving day by day, which is depicted in the following table: 


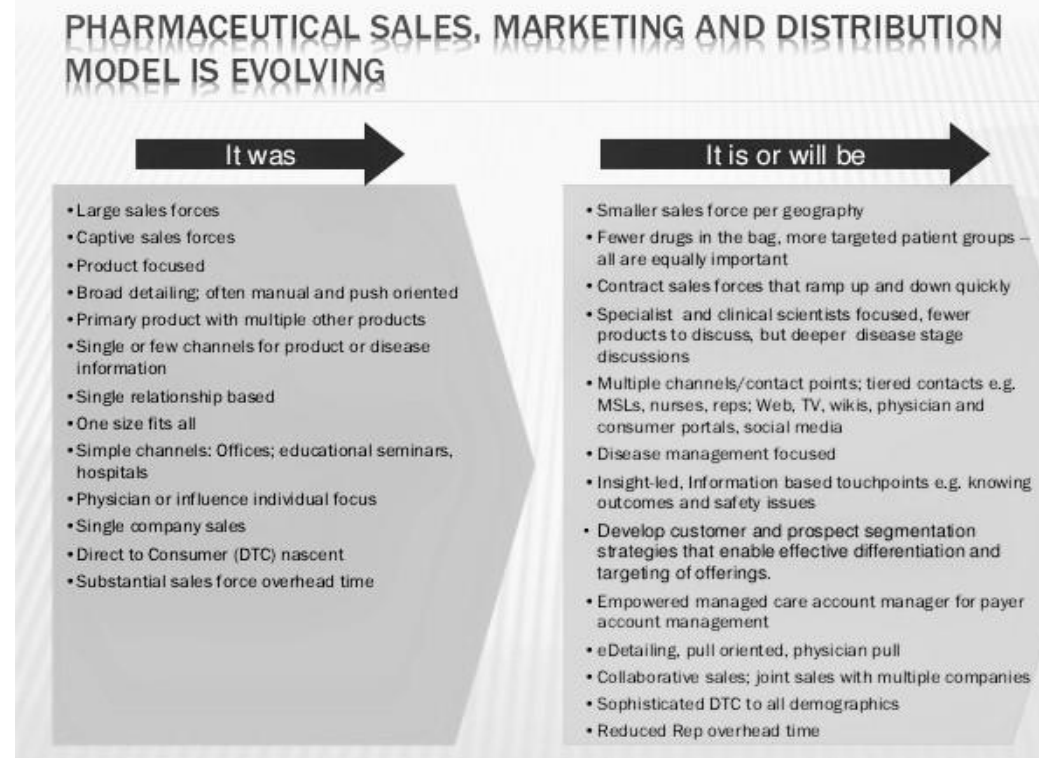

Source: https://www.slideshare.net/frankfangwang/information-management-in-pharmaceutical-industry-58532948

\section{Steps in Developing Effective Communication:}

i) Recognizing the Target Audience: A communicator has to have a clear target in mind. In case of pharmaceutical detailing one has to see whether the detailing is being done to general practitioner or a specialist. On the basis of target physician (GP's or specialist) the depth of detailing is being decided.

ii) Determining the Communication Objectives: Once the target group has been characterized, the advertising communicator must choose what reaction is looked for. Obviously, in numerous cases, the last reaction is buy. Whereas in case of pharmaceutical the outcomes is to prescribe for which it is necessary that the physician gets convinced for that the physician who just have basic knowledge about the product should be told in detail and the one who has built liking for product may be looking for one good reason to prescribe that product.

iii) Designing a Message: After identifying the target audience and its needs the communicators moves further to design a message .This message is designed on the basis of AIDA model which stands for Attention, Interest ,Desire and Action but in case of pharmaceuticals the Desire should be replaced with Decision, decision to prescribe that product.

iv) Choosing Media: The communicator now should choose proper channels for communicating or informing about the product. There may be two types of marketing tools adopted by pharmaceutical organization i.e. in-clinic, out-ofclinic.

a. Personal Communication Channels: Channels through which at least two individuals discuss straightforwardly with one another, whether eye to eye, by phone, via mail, or by means of the web.

b. Word-of-mouth Influence: Personal correspondence about an item between target purchasers and neighbours, companions, family individuals, and partners.

c. Non-individual Communication Channels: Media that convey messages without individual contact or input, counting significant media, radio, and seminars.

v) Selecting the Message Source: In either in-clinic or out-of-clinic communication, the message's effect on the objective group of onlookers is additionally influenced by how the gathering of people perspectives the communicator. Messages conveyed by very trustworthy sources are more influential.

vi) Collecting Feedback: After sending the message, the communicator need to research whether the message has reached to the extent expected. Research could be carried out by marketing and sales management personnel and while interacting with few of the targeted physician they can get idea whether the message was effectively communicated or not and were the queries of doctors resolved by the same.

\section{Challenges faced by Pharma Industry:}

1. Regulatory Barrier: US FDA is a regulatory authority which closely regulates the Pharmaceutical marketing by assuring that the promotional material are accurate, fairly balanced and only limited information which has been approved by FDA is being transferred. Many Pharmaceutical industries has adopted their own 
guidelines which have specified standards led down for interaction with health care providers and appropriate Direct-to-Consumer (DTC) marketing. One of the division of FDA i.e. Drug Marketing \& Communication (DDMA) which regulate the promotion of prescription drugs advertisement \& help assure that the ads are in compliance with the FDA's rules and regulations.

2. Doctors readiness: According to survey carried out by (BCG) Boston Consulting Group and Tufts Centre for Study of Drug Development found that from amongst the various factors only $13-14 \%$ physicians said that pharmaceutical representative have a major impact. Thus choosing a competent sales force does not resolve the problem of convincing doctors to prescribe the medicine within a short period of detailing, instead nowadays pharmaceutical organization has adopted some strategies like giving free samples to doctors as a test marketing to make doctor sure about the effectiveness of that medication, and depending upon the doctors profile the sales reps are trained to detail in different ways to different doctors.

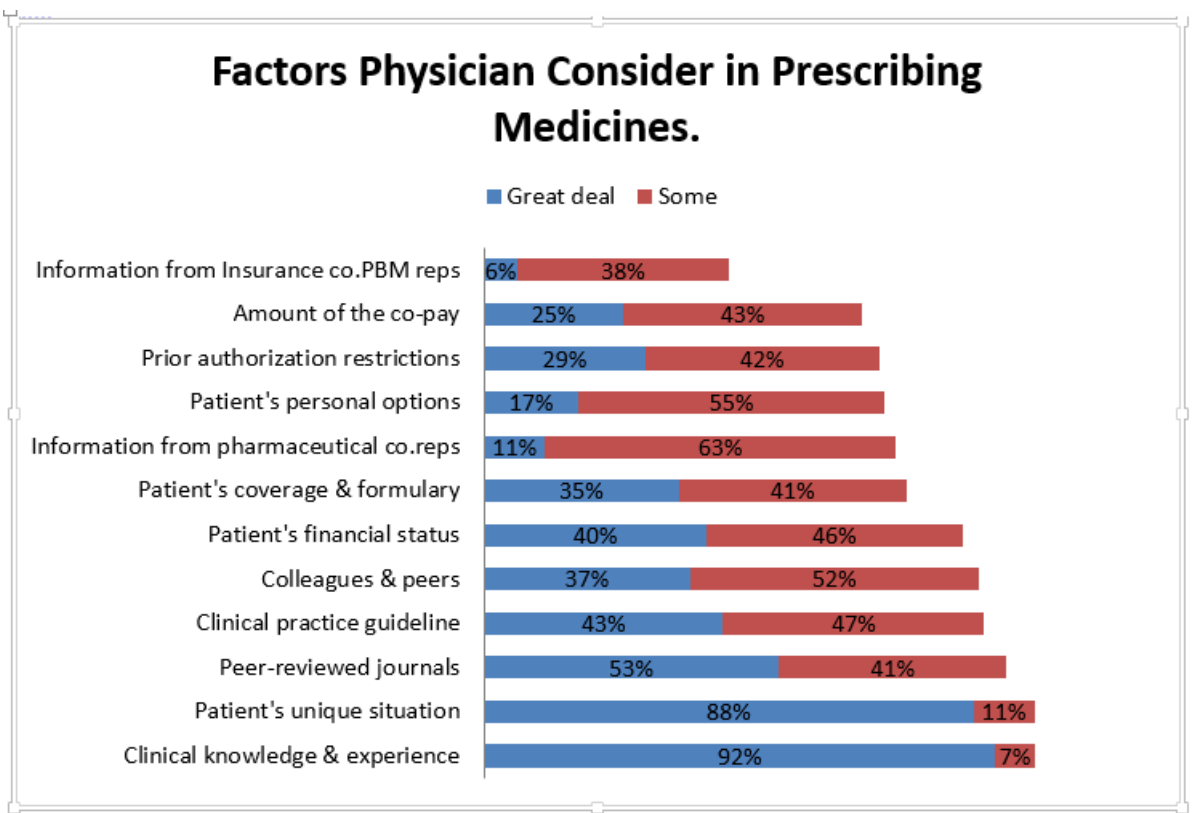

Source: https://www.slideshare.net/Jorgeventura2014/marketing-and-promotionfacts071108final

Due to these restrictions it's difficult to implement all the promotional tools synergistically as that of consumer products. But still there are few tools that can be used together in pharmaceutical marketing by considering that it does not violet any law led down by government of particular country. This tools include

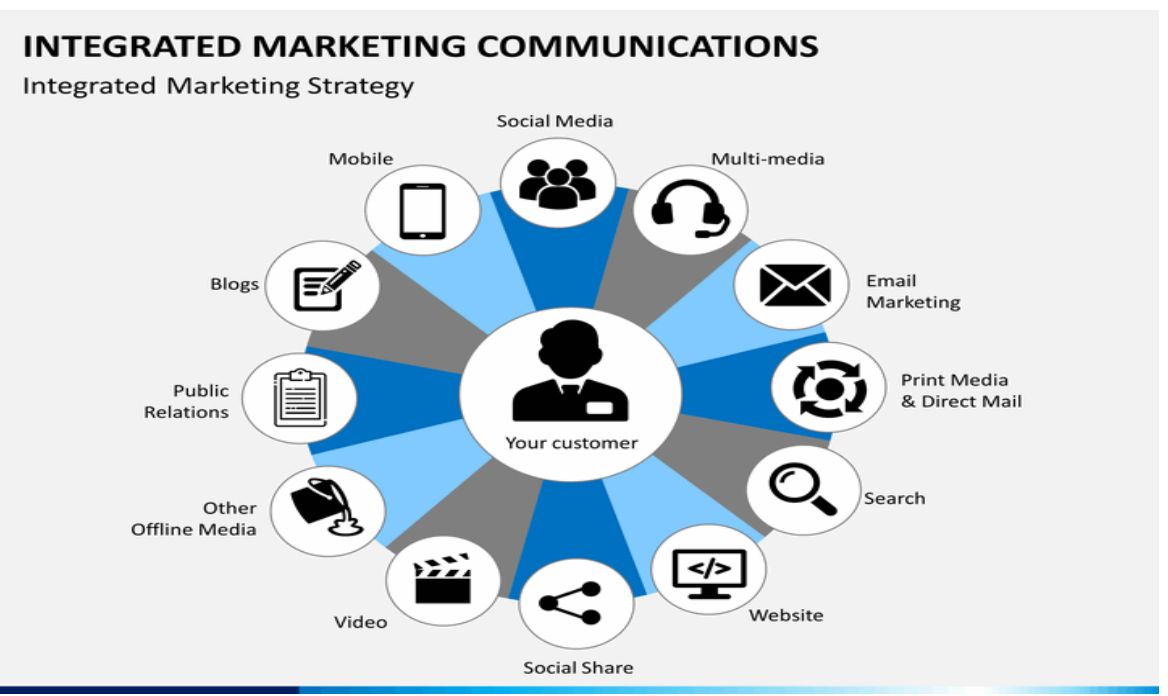

Source: https://www.sketchbubble.com/en/powerpoint-integrated-marketing-communications.html 
1. Internet Based Drug Promotion: Using Corporate Blogs, Social Network Webs and Many Other Online Methods Pharmaceutical industry is focusing on the advantages of the internet and the development of new media forms to promote their products. Electronic detailing, interactive websites, email prompts and viral marketing campaigns using social networking sites such as YouTube, My Space and Face book are among the tools being used.

2. Electronic Detailing: With the technological development, many existing methods and practices has been either replaced or modified in combination with technologically developed methods. Electronic detailing (e-detailing) is one of the methods of drug promotion introduced few years back as technologically develop tool. In pharmaceutical industry it has been introduced as a new communication channel for the promotion of drugs among the physicians. For e-detailing digital technologies like internet, video conferencing, and interactive voice response are adopted to interact with physicians.

i. The chance to get some answers concerning the thing and the treatment at the time picked by a specialist and in this manner invaluable (i.e. on the expert's terms),

ii. cut down costs of reaching the social occasion of individuals when appeared differently in relation to other advancing trades works out,

iii. adjusting more about the specialists and medication authorities and their slants,

iv. Growing the quality and appeal of visits by restorative agents.

v. E-detailing presentations may show up as:

vi. An intelligent media presentation,

vii. A video presentation,

viii. A static presentation with instinctive segments.

3. Personal Selling: Marketing is just not selling product to the customer but it is also making profitable lifetime relationship with them .In Pharmaceutical marketing or promotion the role of making and maintaining genuine relation with people is the part and parcel of sales force The sales person is the only person who dives all the movements of the product. So it is mandatory for the sales representative to be dominant, creative, and strategic and must have ability to convince physician by providing right knowledge about the product and telling the advantages over the competitors. For this reason sales person must have some selling styles like satisfying customer needs, should be able to solve query, handling objection, etc. Personal selling is carried in eight steps which includes Prospecting, Pre-approach, Approach, assign the needs, presentation, handling objection, purchase decision, follow up. Personal selling becomes a easiest tools if sales rep follow $4 \mathrm{C}$ 's Convince, Convert, Consolidate \& Consistent approach.

4. E-Sampling: Sampling is the best promoting tools by which specialists can begin the treatment quickly and test the resistance of the product on their patients as per the condition of disease. It likewise helps the specialists to attempt it as a standard practice for the specific brand also, perceives the name of the brand as it keeps on resounding in their brain. With the advancement of the technology request of physical supply of the samples can be easily made by the doctors using online portals on laptops or mobiles. This has changed the scenario of availability and delivery of products. Doctors may distribute samples to patients for several reasons-for instance, to get patients started on therapy right away, to optimize dosing or choice of drug before committing to a particular course of treatment, and sometimes to help patients who might not be able to afford medicines on their own. A 2008 KRC Research survey found $69 \%$ of physicians believe free drug samples are either always useful $(52 \%)$ or often useful $(17 \%) .21$ Ninety-five percent of physicians surveyed agreed that samples allow patients to start immediate treatment and $84 \%$ said that samples provide them with useful first-hand experience. According to the chairman of the Asthma and Allergy Foundation's Medical- Scientific Council, samples are "an important way of trying to find out which [medicines] work for patients.

5. Sponsorship: Organizations additionally attempt to make indirect payment to the specialists by different backhanded ways i.e. for clinical trials, national and global seminars and symposia sponsorships, free therapeutic camps, conducing lectures for health care providers (physicians).Some of the health care products which are OTC also adopted the sponsorship strategy for promotion like Revital capsules by Ranbaxy, many other pain reliever products sponsor the national and international sports event this helps them to generate sales and gain profit.

\section{Facts and Figures of Pharmaceuticals spending on promotion}

The survey conducted by IMS in 2006 reported that promotional activity spending of Pharmaceuticals totalled to $\$ 12.0$ billion Furthermore ,the entire industry's DTC advertising (such as magazines \& television) accounts for $\$ 4.8$ billion of total promotion. The remaining accounts for $\$ 7.2$ billion which was spent on office promotion, hospital promotion and journal advertise.

Examples of Few Pharmaceutical Companies that have adopted Integrated Promotion Strategy: 
Pfizer's one of the patented product was promoted using Direct-To-Consumer (DTC) advertisement (radio, television) .Pfizer launched a massive campaign in order to educate people and branding Viagra. Merck for its osteoarthritis drug Vioxx adopted public relation approach by hired a celebrity Dorothy Hamill. Whereas AstraZeneca utilized new technology to promote Zomig an anti-migraine by broadcasting its commercial with interactive television because of which interested individual try to gain information and also get connected to brand's web site Direct/Viral email campaign are also adopted by companies for some new prescription drug products by emphasising on its benefits and results. Various healthcare OTC products started use of IMC eg: Revital a nutrition supplement which was promoted using DTC advertisement, sponsorship strategy and also hiring celebrity, Volini, Iodex which are pain relievers are also being promoted by the same tools and with the help of sports person.

\section{Conclusion}

The concept of having an integrated marketing communications is all about effectively coordinating your efforts to produce a sale in a targeted market. This concept applies to the pharmaceutical industry for introducing the product in market and also helps to increase the sales of product. With the increasing competition pharmaceutical industry need to evolve new marketing tools in order to make patients and physicians aware of new treatments and also to gain profit. For a company's drug's to secure market category customer-centric brand communication plays an important role. In order to convey consistent and powerful messages to all stakeholders, especially patients Integrated Marketing campaigns are adopted by pharmaceutical companies. To create a new marketing or sales model for future, it should start by analysing its own value chain to recognize opportunities for working more closely with healthcare and providers, for example collaboration with the governments, patients and health insurance by ensuring that it has social and economic value.

\section{References}

1. Alkhateeb FM, Doucette WR., "Electronic Detailing (edetailing) of Pharmaceuticals to Physicians: A Review" from ProQuest Central database. 2008; 2(3):235-45.

2. Butterworth-Heinemann.Pickton, D. and Broderick, A. (2001) Integrated Marketing Communications. Pearson Education.

3. Darko Pantelic, "Internet as a Medium of Pharmaceutical Companies Promotional Activities", Vol. 4 (2009), No. 1,pp. 029-037

4. Hartley, B. and Pickton, D. (1999) Integrated communication requires a new way of thinking. Journal of Marketing Communications, 5, 97-106.

5. Masterman, G.R. (2004) Strategic Sports Event Management.

6. Panigrahi, A. Kumar, L, "Communication with doctors: empowering Pharma field force with modern marketing techniques" Asian Journal of Management Research, ISSN 2229 - 3795, Volume 5 Issue 2, 2014.

7. Rashid Saeed, Bilal Naeem, et.al, "Integrated Marketing Communication: A Review" September, 2013 VOL 5, NO 5.

8. Rizwan Raheem Ahmed, Vishnu Parmar, Nawaz Ahmad, Usman Ali Warraich, Imamuddin Khoso, "The Communication Mix in Pharmaceutical Marketing" The Pharma Innovation Journal 2014; 3(5): 46-53.6

9. Shakeel-Ul-Rehm ,Dr.M.Syed Ibrahim, "Integrated Marketing Communication and Promotion", Journal of Arts, Science \& Commerce, E-ISSN 2229-4686 ISSN 2231-4172

10. Shimp, T.A. (1997) Advertising, Promotion, and Supplemental Aspects of Integrated Marketing Communications, 4th edition. The Dryden Press.20, 2013

11. Yaw Brew, Samuel Ayittah Kwabena, and Samuel, "Analysis of Distribution Channels in the Pharmaceutical Industry in Ghana: the Case of Aryton Drugs Ltd. in the Greater and Eastern Regions", European Journal of Business and Management. 